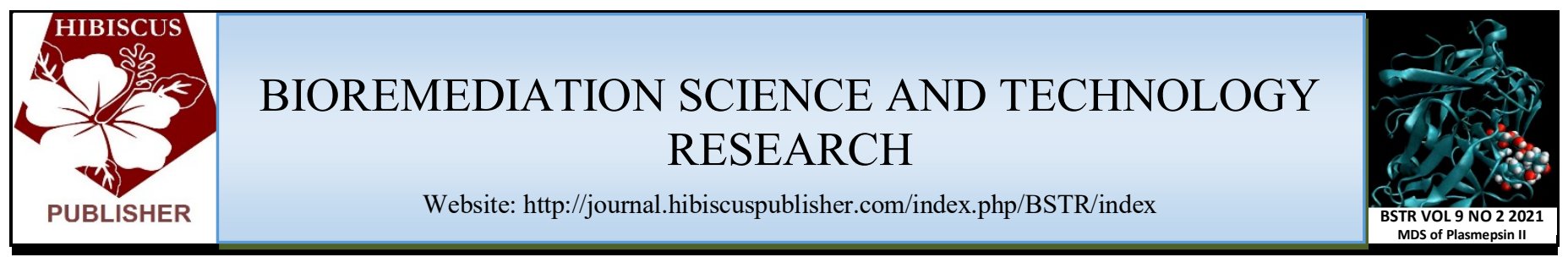

\title{
Phytoremediation of PAHs in Contaminated Soils: A Review
}

\author{
Ibrahim Alkali Allamin $^{1 *}$ and Mohd Yunus Shukor ${ }^{2}$ \\ ${ }^{1}$ Department of Microbiology, Faculty of Sciences, University of Maiduguri, P.M.B. 1069, Maiduguri, \\ Borno State, Nigeria. \\ ${ }^{2}$ Department of Biochemistry, Faculty of Biotechnology and Biomolecular Sciences, Universiti Putra Malaysia, \\ 43400 UPM Serdang, Selangor, Malaysia. \\ *Corresponding author: \\ Dr. Ibrahim Alkali Allamin, \\ Department of Microbiology, \\ Faculty of Sciences, \\ University of Maiduguri, \\ P.M.B. 1069, \\ Maiduguri, \\ Borno State, \\ Nigeria. \\ Email: ibnallamin@gmail.com / ibnallaminmcb@unimaid.edu.ng
}

\begin{tabular}{l}
\hline HISTORY \\
Received: $15^{\text {th }}$ Aug 2021 \\
Received in revised form: $24^{\text {th }}$ Oct 2021 \\
Accepted: $14^{\text {th }}$ Nov 2021 \\
\hline KEYWORDS \\
Bioremediation \\
Phytoremediation \\
PAHs \\
Soil \\
Pollution
\end{tabular}

\section{INTRODUCTION}

Petroleum-based commodities are the primary source of energy for manufacturing and everyday living throughout the age of industrialization. The overtime overdependence on this has led to the contamination of the ecosystem by hydrocarbons caused by spills and leaks that occur throughout the process of petroleum exploration, production, refining, transportation, and storing [1]. Together to manmade actions that discharge hydrocarbon emissions into the atmosphere (biogenic and geochemical), natural crude oil leakage contributes to the discharge of 600,000 to 700,000 metric tonnes per year. Benzene, toluene, ethylbenzene and xylene (BTEX) and Polycyclic aromatic hydrocarbons (PAHs) are among the most powerful environmental pollutants among all petroleum hydrocarbon pollutants, and they are also known as persistent organic pollutants (POPs) because of their long-term effects on the environment. PAHs, which have got aromatic rings bonded together, are found all over the world. In addition to the operations of the oil and gas industry, volatile hydrocarbons are generated when firewood, coal, oil, and gas are burned inefficiently [2-4]. The United States Environmental Protection Agency (U.S. EPA) has designated sixteen (16) PAHs as "priority pollutants" and monitors industrial effluents for these contaminants on a constant basis [5]. One of sixteen priority PAHs identified by the EPA is benzo[a]pyrene, which is the most powerful carcinogen. Because these contaminants are very lipophilic, they can't be dissolved in water, owing to their resistive character. Hence, their biomagnification occurs. Because they have been shown to be immunotoxic, mutagenic, carcinogenic and teratogenic, PAHs represents a serious threat to human health as well as the ecosystem. Possible restoration solutions have been created and used to overcome this worldwide issue because to rising concern for health of human health and the ecosystem [6,7]. (10)There are four sorts of remediation procedures for petroleum hydrocarbon damaged soil: thermal, chemical, biological and physical.

Existing restoration approaches for petroleum oil damaged sites suffer from a number of problems, including low efficiency, increased costs, and the development of significant amounts of sludge. When contaminants are degraded or transformed into carbon dioxide, inorganic salts, water or other metabolites by the employment of microorganisms (mostly fungus and bacteria), bioremediation is being used as a process $[8,9]$. Work in the recent 10 years has concentrated on the application of a mix of remediation approaches for soils treated by petroleum oil [10]. Remediation solutions for cleaning up contaminated sites caused 
by crude oil, diesel, and gasoline have been studied across the world.

\section{Oil refinery waste as source of $\mathrm{PAH}$ pollutants}

Petroleum processing plant turn unrefined petroleum oil to a huge range of goods, including gasoline, jet fuel, and diesel fuel as well as lubricating oil, asphalt and waxes, among others. Petroleumbased compounds such as cycloalkanes, alkanes, PAHs and BTEX are discharged into the air during the purification process. As xenobiotic chemicals, benzene and a number of polycyclic aromatic hydrocarbons (PAHs) are considered POPs or persistent organic pollutants [11]. Carbon and hydrogen atoms, as well as $\mathrm{N}, \mathrm{S}$, and $\mathrm{O}$ atoms, make up PAH. However, due to the low vapor pressure of PAHs and their limited water solubility, making them difficult to disperse in the atmosphere and to be absorbed into the body. Their structure includes two or more aromatic ring fused together in an angular, linear or clustered configuration. An angular configuration of PAHs makes them more robust than a straight one. Molecular weight varies from 166 to 332 for most PAHs on the market [12].

The PAHs molecule's biological stability is due to the dense electrons presence on both sides of the ring structure. As a result, nucleophilic attack to PAHs is more difficult than any other hydrocarbons found in the atmosphere. The solubility of PAHs has been found to diminish with the addition of benzene rings $[13,14]$. PAHs become more resistant due to a rise in molecular mass, which enhances hydrophobicity and lipophilicity while decreasing solubility in water and vapour pressure. To put it another way, the bioavailability of high-molecular-weight PAHs are less and more difficult for microorganisms to break down than PAHs having lower molecular weights. Furthermore, the high molecular weights PAHs are more carcinogenic, mutagenic and teratogenic than low molecular weight PAHs [15-17].

\section{Chronic sickness due to PAHs}

The threat of aromatic hydrocarbon pollutants to people varies depending on the kind and quantity of these pollutants in petroleum refinery effluent. The most common negative effects of exposure to these toxins include nausea, eye irritation, vomiting, and diarrhoea. Increased levels of a pollutant mixture in the workplace produce inflammation and skin irritation. Anthracene, naphthalene, and benzo[a]pyrene are all skin sensitizers. Naphthalene is known to cause cancer. They may cause allergic reactions in both animals and humans [18,19]. Mono- and poly-aromatic hydrocarbon pollution has been found to irreversibly damage human tissue such as the kidneys, lungs, and liver. It may also cause respiratory issues such as asthma. Cataract abnormalities and dermal exposure can produce redness and skin irritation [20-22]. Red blood cells may deteriorate when exposed to high concentrations of naphthalene. All tumours, abnormalities, developmental disorders, and malignancies are caused by cellular damage [23].

\section{Teratogenicity}

Teratogenicity has an impact on the development of an embryo or foetus. Many aromatic hydrocarbons have been discovered as extremely harmful, including naphthalene, benzene, benzo[a]anthracene, and benzo[a]pyrene. Low birth weight and birth abnormalities have been linked to benzo[a]pyrene exposure during pregnancy. Pregnant women who are exposed to PAHs risk having a kid with premature birth, early birth, developmental delays, and congenital heart abnormalities [24]. PAHs have been associated to asthma, lower IQ at the age of three, and behavioural difficulties between the ages of six and eight $[25,26]$. When a baby is exposed to PAHs, the DNA in his or her cord blood is harmed [25].

\section{Genotoxicity}

Most PAHs discovered in petroleum refining byproducts are not carcinogenic in and of themselves. However, epoxides and dihydrodiols are produced when they are digested with other parts, which may result in a genetic abnormality. The binding of aromatic hydrocarbon dihydrodiols and epoxides to DNA causes a "mutation" of the nucleotide codon. PAHs have been proven to produce genotoxicity in rats and in vitro testing on mammalian cell lines, including human cell lines [27]. PAH-induced base pair substitution results in DNA loss, frameshift mutation, sphase arrest, and other chromosomal changes. PAH compounds such as diolepoxides, quinines, and conjugated hydroxyalkyl may occupy nucleophilic centres in macromolecular structures. The toxicity of PAHs can be investigated using the benzo[a]pyrene model chemical $[28,29]$.

\section{Carcinogenicity}

Carcinogenic substances and hydrocarbon pollutants can be found in oil refinery waste. Tumors and malignancies are caused by their attaching to cellular proteins or DNA. During metabolism, they are converted into dangerous epoxides and dihydrodiols, which can lead to cancer [30]. According to the toxicity levels, two, three, and seven-ring PAHs are less carcinogenic than four, five, and six-ring PAHs. Aromatic hydrocarbon pollutants, such as benzene, have been linked to skin, lung, bladder, and stomach malignancies. An aromatic amine present in the structure of PAH chemicals is considered to increase their carcinogenicity. Benzo[a]pyrene is the most extensively utilised PAH that has been related to cancer in both people and animals [29].

Dimethylbenz[a]anthracene, for example, is carcinogenic due to the addition of alkyl groups to the fundamental PAH structure. The United States Environmental Protection Agency has classified the seven PAHs listed below as "probable human carcinogens" (EPA). Epoxide and diol bind to DNA covalently $[31,32]$. Long-term exposure to PAHs has been demonstrated to induce lung cancer in humans. PAHs in food cause colon cancer, and dermal exposure promotes skin cancer [33-35]. Certain PAHs have been found in animal studies to cause cancer. According to animal studies, skin, lung, bladder, liver, and stomach cancers are on the increase, as are injection-site sarcomas.

According to animal research, PAHs may also disturb the haematological and immunological systems, as well as the reproductive, neurologic, and developmental processes in animals. Because most exposures to PAH mixtures are present, it is difficult to ascribe documented health outcomes to specific PAHs in epidemiological study. The risk of lung, skin, and bladder cancer increases with $\mathrm{PAH}$ exposure. According to epidemiological research, those who have been exposed to PAH have a higher chance of developing skin, lung, bladder, and stomach cancers. The first human PAH-related epidemiological study, which focused on the deaths of coal carbonization and gasification workers, was published in 1936 by researchers in Japan and England. Following further study in the United States, researchers discovered that coke oven workers had a higher mortality risk for lung cancer as well as a higher mortality rate for genitourinary system cancer. According to later experimental studies, soot PAHs may have been responsible for the greater prevalence of scrotal cancer observed by Percival Pott among London chimney sweeps. 


\section{Immunotoxicity}

Cancer can be induced directly or indirectly by the immune system being weakened by aromatic hydrocarbon pollutants found in the environment, such as MAHs and PAHs. When PAHs are present in the environment, rats' immunological responses are suppressed. Immunosuppression has been connected to the emergence of infectious illnesses. The production of cytokines, which are inflammatory mediators, increases as a result of this medication. Under certain conditions, an autoimmune or hypersensitive reaction can occur [36]. Several experimental studies have shown that contaminated food, which may contain PAHs, can cause immunotoxicity. In some cases, PAHs have been shown to produce DNA adducts in the lungs [26,37].

\section{PAHs as soil contaminant}

Chemicals generated by industry, certain agricultural practices, and poor waste management all contribute to the introduction of organic contaminants into the soil. The long-term stability of these chemicals in soil poses a risk to human and animal health [38]. PAHs, which are semi-volatile organic molecules consisting of carbon and hydrogen and organised to form 2 or higher number of benzene rings [39], come in a variety of forms. PAHs are organic chemicals that are either volatile or semivolatile. Other elements such as nitrogen, chlorine, oxygen, and sulphur may also be present in aromatic heterocyclic compounds. PAHs can be found in a wide range of environmental compartments.

Natural and man-made factors, such as coal, oil, volcanic eruptions, and industrial operations, as well as automotive traffic and residential heat sources, all contribute to their continuous existence. Human activities have increased the amount of these toxins in all major environmental media (water, air, and soil) over the last century [40]. Because of their hydrophobic qualities, PAHs can survive in the environment and accrue in the food chain [41]. Numerous PAHs were declared to be possible or likely human carcinogens by the International Agency for Research on Cancer (IARC) in 1987 [28]. Toxicities, mutagenicity, teratogenicity, carcinogenicity and teratogenicity, among other aspects, put biological creatures at danger [42].

Despite the fact that PAHs are photosensitive and photodegradable, their physicochemical features lead them to damage the environment for a lengthy period of time after exposure to light. As a result of their limited water solubility and intricate structure, the compounds are resistant to microbial breakdown; nonetheless, some bacteria may metabolize them and utilise the carbon source they provide for development notwithstanding this resilience. Gram-positive and gramnegative bacteria are both capable of degrading PAHs due to the engagement of intracellular enzymes in their metabolism: In contrast to Burkholderia (-proteobacteria), Mycobacterium is capable of degrading PAHs with two or three aromatic rings with great ease; Mycobacterium, on the other hand, is capable of degrading PAHs with a greater number of aromatic rings with relative ease [38].

Lignolytic fungi can perform these metabolising methods as an alternative for bacteria, and they may be more effective than some bacteria because this fungus contains special enzymes (lignin peroxidase, manganese peroxidase, laccase) that play an important role in the initial attack on high-molecular-weight polycyclic aromatic hydrocarbons (PAHs) that are found in the soil. According to Bumpus and colleagues, the earliest investigations on the utilisation of $\mathrm{PAH}$ biodegradation by ligninolytic fungi date back to 1985 , when Phanerochaete chrysosporium partly decomposed benzo[a]pyrene. Trametes,
Bjerkandera, Phanerochaete, Nematoloma, Irpex, Coriolus, and Pleurotus have all been implicated with PAH degradation later on. Extracellular ligninolytic enzymes such as Mn-peroxidase, lignin peroxidase, Laccase and versatile peroxidase, and laccase are responsible for these fungi's capacity to breakdown PAHs.

Decomposition of lignin and subsequent xenobiotic detoxification by fungal laccases and peroxidases has been hypothesised to play a crucial role in fungi's ability to decompose wood and litter. Native bacteria in soils and sediments are much more likely to further degrade polar and water-soluble compounds, such as quinones, produced by these enzymes. Understanding the metabolites produced by fungal metabolism is essential for verifying soil bioremediation. As nutrients for microbial communities, quinonic intermediates are mineralized to carbon dioxide in soil. Polymerization and incorporation into the humic soil pool are further possible outcomes. Fungal enzymes degrade PAHs at varying rates and in varied amounts depending on a range of parameters such as oxygen availability, soil nutrients, $\mathrm{pH}$, temperature, cell transport properties, the molecule's molecular structure, and chemical breakdown in the soil [43].

The use of various forms of compost and bio-augmentation with a range of fungal species for soil bioremediation and bioaugmentation is currently being researched. Because of their propensity to degrade polychlorinated biphenyls (PCBs) and other contaminants, fungal species, in addition to bacteria, may be utilised in bioremediation approaches [38]. Fungi that can grow on a variety of substrates and release extracellular hydrolytic enzymes that can infiltrate polluted soil and extract hydrocarbons may be successfully employed to break down particle organic pollutants (PAHs) [43].

\section{Phytoremediation}

Despite the fact that the term "phytoremediation" was coined in 1991, the first phytoremediation studies were conducted in the 1950s of the twentieth century. Plants are used in this strategy to eliminate toxicants from water and soil and render them safe. This is due to the fact that environmental pollution poses significant health risks and has an effect on health of human where numerous PAHs are mutagenic, carcinogenic, teratogenic and detrimental to children endocrine and neurological systems. Physicochemical approaches for repairing the various matrices have been used, but they have significant limitations. Conventional procedures, for example, are costly, require extensive processing, and alter soil conditions, wreaking havoc on the local vegetation. This publication promotes phytoremediation as a relatively new approach with low longterm expenses [42].

Green plants, such as Brassica juncea, Thlaspi caerulescens, or Helianthus annuus, and including Salix spp. or Populus, which are woody species. Plants are used in phytoremediation to remove, uptake, or render harmless various environmental pollutants in water and soil, such as organic compounds, heavy metals, and including radioactive compounds [44]. Other advantages include a lower danger of contamination dispersal and the possibility to utilise phytoremediation on a wide range of polluted sites without digging unclean areas [45]. Plant species, pollutant type, bioavailability, and soil conditions all have an impact on the processes and performance of phytoremediation. Plants that are "hyperaccumulators" are thought to be more effective in phytoremediation procedures. They can endure and collect metals and organic substances found in soil, such as PAHs, although their biomass production rate is 
modest [46]. It is also reliant on the amount of biomass produced by the plant; a big amount of biomass is capable of absorbing a huge number of metals or organic compounds, including PAHs, but it will take many harvests to completely eliminate the plants from the environment. As a result, the number of harvests will affect the overall cost of the operation, including the incineration, disposal or composting of waste biomass.

Despite these obstacles, phytoremediation can be used for a wide range of remediation methods (such as slowness of process and proximity of affected region to root, as well as the fact that many species cannot be planted in extremely contaminated areas). The treated area becomes more desirable to tourists as a result of the environmental and aesthetic benefits of this technology. It is a low-cost option due to the fact that it requires very little work. Resident acceptance is frequently high, and it is straightforward to carry out. Biomass may be used to generate energy and reduce waste in industries such as renewable energies [47] and waste reduction [44].

Phytoremediation is not as frequently employed in Europe, where sales were less than $\$ 300$ million in 2007 , as it is in the United States [48]. According to this report, the results of a rigorous assessment of phytoremediation's potential in practice strongly illustrate the economic viability of the new method pushed by the US Environmental Protection Agency (EPA) in 2001[49]. (US Environmental Protection Agency, 2001) A significant increase in the use of phytoremediation methods in Europe has occurred as a result of the fact that they are more ecologically friendly and cost-effective than conventional environmental remediation processes. Plant-based remediation is extremely cost-effective when compared to conventional technologies such as excavation and landfilling, soil washing with water and solubilizing agents, vitrification of contaminated soil at high temperatures, solidification using stabilising agents and electrochemical separation [50], and other methods of bioremediation.

\section{Phytodegradation}

After pollutants have been assimilated by the root system and deteriorated by enzymes associated with plant metabolic activities, or after they have been incorporated into plant tissues [51], phytodegradation takes place. In the phytodegradation process, enzymes such as dehalogenase degrades chlorinated compounds, peroxidase degrades phenolic compounds, nitroreductase which degrades nitrate and explosives compounds, nitrilase that degrades cyanated aromatic compounds, and phosphatase that degrades organophosphate pesticides. Inorganic pollutants such as chlorinated solvents, herbicides, and polycyclic aromatic hydrocarbons (PAHs) may be remedied using phytodegradation, and surface and ground waters can be recovered using phytodegradation [52]. This has been accomplished by the utilisation of plants from a variety of different kinds. [53] employed the plant species Lupinus luteus in combination with endophytic bacteria to restore landfill soils on the Iberian peninsula that had been contaminated with organic pollutants such as benzo(a)pyrene. There were two experiments planned in a greenhouse: (1) growth on a substrate that had been purposefully contaminated with benzo(a)pyrene, and (2) growth on waste soil as a growing media, both of which were carried out. As a result of this, endophytic bacteria were recovered from the roots and shoots of the plants that were employed in the two greenhouse experiments. Growth, resistance to organic contaminants, and deterioration were among the traits observed. Essentially, the data indicate that when the plants were grown in the presence of benzo(a)pyrene, they did not display any evidence of cytotoxicity; yet, when the plants were grown on waste soil, they did exhibit cytotoxic activity. Others were vulnerable to benzo(a)pyrene and other chemical compounds, whilst others spurred plant growth and were resistant to benzo(a)pyrene and other chemical substances (diesel and PCBs).

\section{Rhizodegradation}

Rhizodegradation is a biodegradation process that happens at the level of the plant's radical apparatus, which is situated in the rhizosphere, which is a soil area adjacent to the plant's radical apparatus. This procedure is referred as rhizodegradation. In the rhizosphere, the activities of bacteria, fungus, and yeasts (research has shown that the number of microorganisms present in the rhizosphere is 100 times more than the number of microorganisms present on the surface) results in the accumulation of micronutrients from the plant's root secretions. Secretions from the roots of plants may be used to help in the recovery and removal of contaminants [51].

In the rhizosphere, it is thought that microorganisms are more widespread as a consequence of the availability of resources such as sugars and amino acids, as well as enzymes and other substances generated by plants, which promote their growth. Moreover, roots give a higher surface area for microbial development as well as a sufficient amount of oxygen to the plant's environment. Taken together, the partnership of microorganisms and plants is beneficial to both parties in the long run. Mycorrhizal fungi are among the many different types of soil microorganisms that may connect with host plants and develop a symbiotic relationship with the plants they contact with. It is at the root system level that the interaction takes place, and there are two forms of mycorrhizae; endomycorrhizae, which occur when the fungus is contained inside the root tissue, and ectomycorrhizae, which occur when the fungus is contained outside the root tissue [54].

Rhizodegradation has both advantages and disadvantages, as is obvious. In addition to its many advantages, rhizodegradation is a process that occurs in the natural environment. Rhizodegradation is less likely than other phytoremediation procedures to cause chemical transfer to other parts of the plant or into the environment. Rhizodegradation may result in toxicant mineralization in certain cases. The next point to mention is that installation and upkeep are inexpensive. In addition to being a slow and ineffective process, rhizodegradation is confined to the surface of the contamination (20-25 cm depth), where the roots' ability to penetrate deeper into the soil may be restricted by the physical structure of the soil. As a result of this, unless a nitrogen fixer, such as Cajanus cajan, is used, the plants may need more fertiliser [55].

For soil remediation, rhizodegradation is especially helpful because it enhances the soil's physical and chemical properties and can be used to remove a wide range of pollutants, such as polycyclic aromatic hydrocarbons, pesticides, polychlorinated biphenyls, and benzene-related chemicals (BTEX compounds) (benzene, toluene, ethylbenzene, xylene). Kandelia candel [56] and Avicennia marina [57] have been studied for their capable of degrading phenanthrene and pyrene through the process known as rhizodegradation. The presence of rhizosphere has been shown to be successful in stimulating the deterioration of PAHs. Before the plants were collected, $10 \mathrm{mg} / \mathrm{kg}$ of phenanthrene and 10 $\mathrm{mg} / \mathrm{kg}$ of pyrene were sprayed to the rhizosphere of Kandelia candel plants in a greenhouse. During the first 60 days of the plant's growth, it was found that polluted sediment degraded phenanthrene and pyrene more rapidly (by $47.7 \%$ and $376.9 \%$, respectively). The highest $\mathrm{PAH}$ degradation rates were found to 
be $3 \mathrm{~mm}$ away from the root zone (56.8 percent phenanthrene and 47.7 percent pyrene). There are three distinct soil zones in the near rhizosphere: the root compartment, the distant rhizosphere, and soil zones (Lu et al., 2011).

A study found that the breakdown of phenanthrene and pyrene in rhizosphere sediments was much higher than in nonrhizosphere sediments. There's also a substantial association (R2 $>0.91$ ) between dissolved organic matter and residual PAHs in both the rhizosphere and nonrhizosphere sediments after 120 days of growth. Soil contaminated with organic pollutants has already been used successfully to grow plants in certain situations. Flavonoids and polyphenols, compounds that activate enzymes in PAH-degrading organisms, were studied for their ability to be produced by several trees at numerous refinery sites. Microorganisms that are naturally present in the rhizosphere aid in the growth of plants. Because of the presence of organic materials, such as root exudates, the rhizosphere has a high level of microbial activity. As a result, the plant's root exudates help microorganisms absorb a nutrient, which in turn improves the plant's performance and the quality of the soil [58].

Plants' interactions with microbes have been shown to have considerable degradative capacity for several organic chemicals, including PAHs. Glutathione (GSH), sugars, or organic acids are conjugated with organic compounds to increase their solubility and enable them to be carried into vacuoles, where they can be further transformed to Carbon dioxide and water by the process of oxidation, reduction, and hydrolysis [59]. Enzymes may aid in the decomposition of contaminants in a number of ways. Monoand dioxygenases, dehydrogenases, hydrolases, peroxidases, nitroreductases, dehalogenases, phosphatases, carboxylesterases, and other enzymes fall under this category. Nature produces these enzymes in the soil, where they could aid in the degradation of a broad spectrum of organic contaminants [48]. Proteomics technologies have been used with appropriate transgenic species of plants to assess the potential for phytoremediation [60]. To illustrate this point, [61] carried out a transgenic test on tobacco plants, which showed a considerable increase in TNT and GTN degradability. Plants designed to resist herbicides, PCBs, nitroaromatic compounds, and other environmental contaminants may be utilised to restore soil that has been harmed by these pollutants.

\section{CONCLUSION}

In conclusion, PAHs toxicity is a well-known fact especially its ability to cause cancer and other diseases on the long term. The removal of PAHs from the environment requires the action of microorganisms and plants in a symbiotic relationship that is able to remediate better than individual organisms alone. The toxicity of other components of PAHs especially heavy metals is a challenge to remediation technology as these toxic ions are known to inhibit the process of bioremediation.

\section{REFERENCES}

1. Bachmann RT, Johnson AC, Edyvean RGJ. Biotechnology in the petroleum industry: An overview. Int Biodeterior Biodegrad. 2014;86:225-37.

2. Andreoni V, Cavalca L, Rao MA, Nocerino G, Bernasconi S, Dell'Amico E, et al. Bacterial communities and enzyme activities of PAHs polluted soils. Chemosphere. 2004;57(5):401-12.

3. Gan S, Lau EV, Ng HK. Remediation of soils contaminated with polycyclic aromatic hydrocarbons (PAHs). J Hazard Mater. 2009;172(2-3):532-49.
4. Guieysse B, Viklund G, Toes A-C, Mattiasson B. Combined UVbiological degradation of PAHs. Chemosphere. 2004;55(11):14939.

5. EPA) USEPA (U S. U.S. Environmental Protection Agency National Contingency Plan Product Schedule January 2017. US Environ Prot Agency Natl Conting Plan Prod Sched January 2017 2017 ;

6. Lamichhane S, Bal Krishna KC, Sarukkalige R. Polycyclic aromatic hydrocarbons (PAHs) removal by sorption: A review. Chemosphere. 2016;148:336-53.

7. Tiwari B, Manickam N, Kumari S, Tiwari A. Biodegradation and dissolution of polyaromatic hydrocarbons by Stenotrophomonas sp. Bioresour Technol. 2016;216:1102-5.

8. Mnif S, Sayadi S, Chamkha M. Biodegradative potential and characterization of a novel aromatic-degrading bacterium isolated from a geothermal oil field under saline and thermophilic conditions. Int Biodeterior Biodegrad. 2014;86:258-64.

9. Varjani SJ. Remediation processes for petroleum oil polluted soil. Indian J Biotechnol. 2017;16(2):157-63.

10. Varjani SJ. Microbial degradation of petroleum hydrocarbons Bioresour Technol. 2017;223:277-86.

11. Meckenstock RU, Boll M, Mouttaki H, Koelschbach JS, Cunha Tarouco P, Weyrauch P, et al. Anaerobic degradation of benzene and polycyclic aromatic hydrocarbons. J Mol Microbiol Biotechnol. 2016;26(1-3):92-118.

12. Blumer M. Polycyclic aromatic compounds in nature. Sci Am. 1976;234(3):35-45.

13. Wilson SC, Jones KC. Bioremediation of soil contaminated with polynuclear aromatic hydrocarbons (PAHs): A review. Environ Pollut. 1993;81(3):229-49.

14. Okere UV, Semple KT. Biodegradation of PAHs in 'Pristine' soils from different climatic regions. J Bioremed Biodegrad. 2012;(6):111 .

15. Cerniglia CE, Heitkamp MA. Microbial degradation of polycyclic aromatic hydrocarbons $(\mathrm{PAH})$ in the aquatic environment. Metab Polycycl Aromat Hydrocarb Aquat Environ. 1989;41-68.

16. Cerniglia CE. Biodegradation of polycyclic aromatic hydrocarbons Biodegradation. 1992;3(2-3):351-68

17. Da Silva M, Esposito E, Moody JD, Canhos VP, Cerniglia CE. Metabolism of aromatic hydrocarbons by the filamentous fungus Cyclothyrium sp. Chemosphere. 2004;57(8):943-52.

18. Kim YM, Ahn CK, Woo SH, Jung GY, Park JM. Synergic degradation of phenanthrene by consortia of newly isolated bacterial strains. J Biotechnol. 2009;144(4):293-8.

19. Ortega-González DK, Cristiani-Urbina E, Flores-Ortíz CM, CruzMaya JA, Cancino-Díaz JC, Jan-Roblero J. Evaluation of the Removal of Pyrene and Fluoranthene by Ochrobactrum anthropi, Fusarium sp. and Their Coculture. Appl Biochem Biotechnol. 2015;175(2):1123-38.

20. Claxton LD, Houk VS, Williams R, Kremer F. Effect of bioremediation on the mutagenicity of oil spilled in Prince William Sound, Alaska. Chemosphere. 1991;23(5):643-50.

21. Samanta SK, Singh OV, Jain RK. Polycyclic aromatic hydrocarbons: Environmental pollution and bioremediation. Trends Biotechnol. 2002;20(6):243-8.

22. Baderna D, Maggioni S, Boriani E, Gemma S, Molteni M, Lombardo A, et al. A combined approach to investigate the toxicity of an industrial landfill's leachate: Chemical analyses, risk assessment and in vitro assays. Environ Res. 2011;111(4):603-13.

23. Desforges J-PW, Sonne C, Levin M, Siebert U, De Guise S, Dietz R. Immunotoxic effects of environmental pollutants in marine mammals. Environ Int. 2016;86:126-39.

24. Ng SP, Conklin DJ, Bhatnagar A, Bolanowski DD, Lyon J, Zelikoff JT. Prenatal exposure to cigarette smoke induces diet- and sexdependent dyslipidemia and weight gain in adult murine offspring. Environ Health Perspect. 2009;117(7):1042-8.

25. Edwards SC, Jedrychowski W, Butscher M, Camann D, Kieltyka A, Mroz E, et al. Prenatal exposure to airborne polycyclic aromatic hydrocarbons and children's intelligence at 5 years of age in a prospective cohort study in Poland. Environ Health Perspect. 2010;118(9):1326-31.

26. Perera FP, Tang D, Wang S, Vishnevetsky J, Zhang B, Diaz D, et al. Prenatal polycyclic aromatic hydrocarbon (PAH) exposure and child behavior at age 6-7 years. Environ Health Perspect. 2012;120(6):921-6. 
27. Thomas KV, Balaam J, Barnard N, Dyer R, Jones C, Lavender J, et al. Characterisation of potentially genotoxic compounds in sediments collected from United Kingdom estuaries. Chemosphere. 2002;49(3):247-58.

28. Cancer IA for R on. IARC monographs on the evaluation of the carcinogenic risk of chemicals to humans. Overall Eval Carcinog Updat IARC Monogr. 1987;(SUPPL. 7).

29. Bhattacharya SS, Syed K, Shann J, Yadav JS. A novel P450initiated biphasic process for sustainable biodegradation of benzo[a]pyrene in soil under nutrient-sufficient conditions by the white rot fungus Phanerochaete chrysosporium. J Hazard Mater. 2013;261:675-83.

30. Schwerdtle T, Ebert F, Thuy C, Richter C, Mullenders LHF, Hartwig A. Genotoxicity of soluble and particulate cadmium compounds: Impact on oxidative dna damage and nucleotide excision repair. Chem Res Toxicol. 2010;23(2):432-42.

31. Mazzeo DEC, Fernandes TCC, Marin-Morales MA. Cellular damages in the Allium cepa test system, caused by BTEX mixture prior and after biodegradation process. Chemosphere. 2011;85(1):13-8.

32. Ghosal D, Ghosh S, Dutta TK, Ahn Y. Current state of knowledge in microbial degradation of polycyclic aromatic hydrocarbons (PAHs): A review. Front Microbiol. 2016;7(AUG).

33. Ambrosoli R, Petruzzelli L, Minati JL, Marsan FA. Anaerobic PAH degradation in soil by a mixed bacterial consortium under denitrifying conditions. Chemosphere. 2005;60(9):1231-6.

34. Veyrand B, Sirot V, Durand S, Pollono C, Marchand P, DervillyPinel $\mathrm{G}$, et al. Human dietary exposure to polycyclic aromatic hydrocarbons: Results of the second French Total Diet Study. Environ Int. 2013;54:11-7.

35. Zafra G, Moreno-Montaño A, Absalón ÁE, Cortés-Espinosa DV. Degradation of polycyclic aromatic hydrocarbons in soil by a tolerant strain of Trichoderma asperellum. Environ Sci Pollut Res. 2015;22(2):1034-42.

36. Gao J, Burchiel SW. Genotoxic Mechanisms of PAH-Induced Immunotoxicity. Molecular Immunotoxicology. 2014. 245-262 p.

37. Arulazhagan P, Vasudevan N, Yeom IT. Biodegradation of polycyclic aromatic hydrocarbon by a halotolerant bacterial consortium isolated from marine environment. Int $\mathrm{J}$ Environ Sci Technol. 2010;7(4):639-52.

38. Winquist E, Björklöf K, Schultz E, Räsänen M, Salonen K, Anasonye F, et al. Bioremediation of PAH-contaminated soil with fungi - From laboratory to field scale. Int Biodeterior Biodegrad. 2014;86:238-47.

39. Marquès M, Mari M, Audí-Miró C, Sierra J, Soler A, Nadal M, et al. Photodegradation of polycyclic aromatic hydrocarbons in soils under a climate change base scenario. Chemosphere. 2016;148:495-503.

40. Jones KC, Grimmer G, Jacob J, Johnston AE. Changes in the polynuclear aromatic hydrocarbon content of wheat grain and pasture grassland over the last century from one site in the U.K. Sci Total Environ. 1989;78(C):117-30.

41. Mollea C, Bosco F, Ruggeri B. Fungal biodegradation of naphthalene: Microcosms studies. Chemosphere. 2005;60(5):63643.

42. Roy S, Labelle S, Mehta P, Mihoc A, Fortin N, Masson C, et al. Phytoremediation of heavy metal and PAH-contaminated brownfield sites. Plant Soil. 2005;272(1-2):277-90.

43. Kadri T, Rouissi T, Brar SK, Cledon M, Sarma S, Verma M. Biodegradation of polycyclic aromatic hydrocarbons (PAHs) by fungal enzymes: A review. J Env Sci. 2015;83.

44. Tahir U, Yasmin A, Khan UH. Phytoremediation: Potential flora for synthetic dyestuff metabolism. J King Saud Univ-Sci. 2015;

45. Mudhoo A, Sharma SK, Lin ZQ, Dhankher OP. Phytoremediation of arsenic-contaminated environment an overview. Green Chem Environ Sustain. 2010;127-49.

46. Van Oosten MJ, Maggio A. Functional biology of halophytes in the phytoremediation of heavy metal contaminated soils. Environ Exp Bot. 2015;111:135-46.

47. Jiang Y, Lei M, Duan L, Longhurst P. Integrating phytoremediation with biomass valorisation and critical element recovery: A UK contaminated land perspective. Biomass Bioenergy. 2015;83:32839.
48. Campos VM, Merino I, Casado R, Pacios LF, Gómez L. Review Phytoremediation of organic pollutants. Span J Agric Res. 2008;6(SPEC. ISS.):38-47.

49. EPA U. 2001;

50. Glass DJ. Economic potential of phytoremediation. Phytoremediation Toxic Met Using Plants Clean Environ. 2000;1531 .

51. Barceló J, Poschenrieder C. Phytoremediation: Principles and perspectives. Contrib Sci. 2003;2(3):333-44.

52. Bamforth SM, Singleton I. Bioremediation of polycyclic aromatic hydrocarbons: Current knowledge and future directions. J Chem Technol Biotechnol. 2005;80(7):723-36.

53. Gutiérrez-Ginés MJ, Hernández AJ, Pérez-Leblic MI, Pastor J, Vangronsveld J. Phytoremediation of soils co-contaminated by organic compounds and heavy metals: Bioassays with Lupinus luteus L. and associated endophytic bacteria. J Environ Manage. 2014;143:197-207.

54. Leung H-M, Wang Z-W, Ye Z-H, Yung K-L, Peng X-L, Cheung K-C. Interactions between arbuscular mycorrhizae and plants in phytoremediation of metal-contaminated soils: A review. Pedosphere. 2013;23(5):549-63.

55. Allamin IA, Halmi MIE, Yasid NA, Ahmad SA, Abdullah SRS, Shukor Y. Rhizodegradation of Petroleum Oily Sludgecontaminated Soil Using Cajanus cajan Increases the Diversity of Soil Microbial Community. Sci Rep. 2020 Dec;10(1):4094.

56. Lu H, Zhang Y, Liu B, Liu J, Ye J, Yan C. Rhizodegradation gradients of phenanthrene and pyrene in sediment of mangrove (Kandelia candel (L.) Druce). J Hazard Mater. 2011;196:263-9.

57. Jia H, Wang H, Lu H, Jiang S, Dai M, Liu J, et al. Rhizodegradation potential and tolerance of Avicennia marina (Forsk.) Vierh in phenanthrene and pyrene contaminated sediments. Mar Pollut Bull. 2016;110(1):112-8.

58. Kavamura VN, Esposito E. Biotechnological strategies applied to the decontamination of soils polluted with heavy metals. Biotechnol Adv. 2010;28(1):61-9.

59. Nunes da Silva M, Mucha AP, Rocha AC, Silva C, Carli C, Gomes $\mathrm{CR}$, et al. Evaluation of the ability of two plants for the phytoremediation of $\mathrm{Cd}$ in salt marshes. Estuar Coast Shelf Sci. 2014;141:78-84.

60. McCutcheon SC, Jørgensen SE. Phytoremediation. Encyclopedia of Ecology, Five-Volume Set. 2008. 2751-2766 p.

61. French CE, Rosser SJ, Davies GJ, Nicklin S, Bruce NC. Biodegradation of explosives by transgenic plants expressing pentaerythritol tetranitrate reductase. Nat Biotechnol. $1999 ; 17(5): 491-4$ 